\title{
Inactivation of Exogenous Surfactant by Pulmonary Edema Fluid
}

\author{
TSUTOMU KOBAYASHI, KEIKO NITTA, MASAYA GANZUKA, SACHIKO INUI, \\ GERTIE GROSSMANN, AND BENGT ROBERTSON \\ Department of Anesthesiology [T.K., K.N., M.G., S.I.], School of Medicine, Kanazawa University, Kanazawa, \\ Japan and Research Unit for Experimental Perinatal Pathology [G.G., B.R.], St. Göran's Hospital, \\ Stockholm, Sweden
}

\begin{abstract}
Modified natural porcine surfactant was mixed with edema fluid sampled from the airways of hyperoxia-exposed adult rabbits. By varying the concentration of surfactant lipids $(10,25$, and $50 \mathrm{mg} / \mathrm{mL})$ and edema fluid proteins $(0-280 \mathrm{mg} / \mathrm{mL})$, we obtained a series of preparations with protein to surfactant lipid weight ratios ranging from 0 to 11.2. The surfactant activity of these various mixtures was analyzed with a pulsating bubble (at a lipid concentration of $10 \mathrm{mg} / \mathrm{mL}$ ) or in experiments on immature newborn rabbits (at lipid concentrations of 25 or $50 \mathrm{mg} / \mathrm{mL}$ ). For the latter purpose, animals were delivered at a gestational age of $27 \mathrm{~d}$ and ventilated with a standardized sequence of insufflation pressures after receiving $0.1 \mathrm{~mL}$ of the surfactant-edema sample into the airways at birth. Nearly complete in vitro inhibition of surfactant (markedly delayed film adsorption and a minimum surface tension of $23 \mathrm{mN} / \mathrm{m}$ during pulsation) was observed at a protein to surfactant lipid ratio of 4.5 . Under in vivo conditions, nearly complete surfactant inhibition (tidal volumes reduced to less than $20 \%$ of the values for littermates ventilated with the same pressure after receiving surfactant without admixture of edema fluid) was documented at a protein to surfactant lipid ratio of 11.2. Our data suggest that the functional properties of an immature neonatal lung, in which serum proteins tend to leak into the airspaces after the onset of ventilation, depend on the stoichiometric relation between surfactant lipids and inhibitory proteins in the lung liquid. (Pediatr Res 29: 353-356, 1991)
\end{abstract}

\section{Abbreviations}

$\mathrm{P} / \mathrm{L}$, protein to surfactant lipid

Surfactant CK, modified natural porcine surfactant

Respiratory distress syndrome of the premature newborn infant is the result of at least two pathophysiologic mechanisms. One is a deficiency of lung surfactant phospholipids and associated proteins, the other is a leakage of serum proteins into the airspaces (1). These two factors are intertwined, inasmuch as ventilation of surfactant-deficient lungs causes epithelial disrup-

Received February 26, 1990; accepted October 24, 1990.

Correspondence: Tsutomu Kobayashi, M.D., Department of Anesthesiology, School of Medicine, Kanazawa University, 13-1 Takara-machi, Kanazawa, Japan 920.

Supported by Grant-in-Aid of the Japan Medical Association, Grant-in-Aid for Scientific Research from the Ministry of Education, Science and Culture of Japan (project no 02454352) the Japan Society for the Promotion of Science, the Royal Swedish Academy of Sciences (travel grants to G.G. and B.R.), the Swedish Medical Research Council (project no. 3351), and Konung Oscar II:s Jubileumsfond. tion (2) and the leaking proteins include potent inhibitors of lung surfactant $(3-6)$. Flooding of the airspaces with inhibitory proteins aggravates the underlying surfactant deficiency and may initiate a vicious cycle making the patient dependent on artificial ventilation for several days or weeks. Inactivation of lung surfactant by leaking proteins is probably an important factor also in the pathogenesis of the adult respiratory distress syndrome and may interfere with the therapeutic effect of surfactant replacement (7).

In the present experiments, immature rabbit neonates were treated with a dose of heterologous surfactant mixed with various amounts of lung edema fluid sampled from adult rabbits with respiratory failure induced by prolonged exposure to hyperoxia (7). Our specific hypothesis was that the improvement of lung compliance (reflected by the tidal volume during artificial ventilation under standardized conditions) usually observed in these animals after administration of exogenous surfactant at birth would be compromised in a concentration-dependent manner by the simultaneous instillation of edema fluid into the airspaces.

\section{MATERIALS AND METHODS}

Preparations of surfactant and lung edema fluid. Surfactant $\mathrm{CK}$ was isolated from porcine lung lavage fluid by a combination of centrifugation, chloroform: methanol extraction, and acetone precipitation (8). For in vitro studies of surfactant inhibition with the pulsating bubble method (9), this surfactant was suspended at a lipid concentration of $10 \mathrm{mg} / \mathrm{mL}$ in normal saline and in five different concentrations of edema fluid in saline, ranging from 8 to $80 \%$. The original edema fluid had been sampled from the airways of hyperoxia-exposed adult rabbits as previously described (7). It had a protein content of $56 \mathrm{mg} / \mathrm{mL}$ (biuret test; Clinanalyzer JCA-MS24, Nihondenshi, Japan) and a phospholipid content of $1.0 \mathrm{mg} / \mathrm{mL}$ (molybdenum blue method, Phospholipids-Test-Wako, Wako Pure Chemical, Osaka, Japan), the latter component probably representing a mixture of surfactant phospholipids and membrane lipids from degenerated epithelial cells. The $\mathrm{P} / \mathrm{L}$ ratio of the five mixtures of edema fluid and surfactant used for the in vitro studies thus ranged from 0.45 to 4.5 (Table 1). Protein electrophoresis of the edema fluid revealed $74 \%$ albumin, $11 \% \alpha_{1}$-globulin, $10 \% \alpha_{2}$-globulin, and $5 \% \beta$ globulin. There was no detectable $\gamma$-globulin peak. Fibrin was removed with the clot that formed spontaneously in the edema fluid soon after sampling (7).

For in vivo studies on immature newborn rabbits, surfactant was suspended at a lipid concentration of either 25 or 50 $\mathrm{mg} / \mathrm{mL}(10)$ in normal saline or in mixtures of edema fluid and saline with protein concentrations ranging from 56 to $280 \mathrm{mg} /$ $\mathrm{mL}$; the higher concentrations of edema fluid were obtained by dialysis against distilled water for $36 \mathrm{~h}$ using a cellulose membrane with a cut-off point of 12000-14000 followed by lyophilization and resuspending of the original material in saline. The 
$\mathrm{P} / \mathrm{L}$ ratio of the mixtures of surfactant and edema fluid used for the animal experiments ranged from 2.2 to 11.2 (Table 2).

In vitro evaluation of surfactant inhibition. The surface properties of the original surfactant preparation and the mixtures of surfactant and edema fluid defined above were determined with a pulsating bubble at $37^{\circ} \mathrm{C}(9)$. Before onset of pulsation, the surface tension of the bubble was recorded during static conditions. Equilibrium surface tension was defined as the value recorded $4 \mathrm{~min}$ after the bubble was formed. Dynamic surface properties were then evaluated during $5 \mathrm{~min}$ while the radius of the bubble oscillated from 0.55 to $0.40 \mathrm{~mm}$ (corresponding to $50 \%$ surface compression) at the rate of $40 / \mathrm{min}$. Values for surface tension at maximum and minimum bubble size were recorded continuously during the period of pulsation. After 5 min, the pulsation was stopped at maximum bubble size. The surface tension recorded $1 \mathrm{~s}$ later was related to the equilibrium surface tension determined before pulsation as a parameter of surface adsorption rate.

Animal experiments. A total of 108 immature newborn rabbits were obtained by hysterotomy at a gestational age of $27 \mathrm{~d}$ and tracheotomized immediately after delivery. Via the tracheal cannula, the experimental animals received $0.1 \mathrm{~mL}$ of surfactant material suspended in saline or edema fluid at the concentrations mentioned above; littermate controls received no material via the airways. A survey of the various groups of animals is given in Table 2 (the number of animals receiving surfactant suspended in concentrated edema fluid is lower because the supply of this particular vehicle was limited).

The animals were then kept at $37^{\circ} \mathrm{C}$ in a system of body plethysmographs (11). They were paralyzed with intraperitoneal pancuronium bromide, and subjected in parallel to pressureconstant ventilation with $100 \%$ oxygen using a Servo-Ventilator 900B (Siemens-Elema, Solna, Sweden), set at a frequency of $40 /$ min and $50 \%$ inspiration time. The insufflation pressure was first raised to $35 \mathrm{~cm} \mathrm{H} \mathrm{H}_{2} \mathrm{O}$ for $1 \mathrm{~min}$ to facilitate the initial expansion of the lungs and to enhance the distribution of the exogenous material in the peripheral airspaces. Thereafter the animals were ventilated with a series of insufflation pressures $(25$ to 20 to $15 \mathrm{~cm} \mathrm{H}_{2} \mathrm{O}$ (12). After $5 \mathrm{~min}$ of ventilation at each ventilator setting, tidal volumes were recorded with a pneumotachygraph connected to the individual plethysmograph box. ECG recordings were obtained at the end of the experiment from s.c. needle electrodes.

Preparation and histologic examination of lungs. At the end of the experiments, the animals were killed with an overdose of pentobarbital sodium. The abdomen was opened and the diaphragm inspected for evidence of pneumothorax. Thereafter the thorax was opened and the lungs were fully inflated with air at a transpulmonary pressure of $30 \mathrm{~cm} \mathrm{H}_{2} \mathrm{O}$. The distending pressure was then lowered to $10 \mathrm{~cm} \mathrm{H} \mathrm{H}_{2} \mathrm{O}$, which was maintained while the lungs were fixed with $10 \%$ neutral formalin infused for 30 min into the pulmonary arterial system at a pressure of $65 \mathrm{~cm}$ $\mathrm{H}_{2} \mathrm{O}$. The lungs were embedded in paraffin for histologic evaluation of alveolar expansion. The volume density of the alveolar compartment was determined by point-counting, using total parenchyma as reference volume.

Statistical methods. Differences in surface properties, tidal volume and alveolar volume density were evaluated with the Wilcoxon two-sample test (two-tailed), differences in survival rate with the $\chi^{2}$ test.

\section{RESULTS}

Surface tension measurements. Data on surface adsorption rate and dynamic surface properties of surfactant suspended in saline or various concentrations of edema fluid are shown in Table 1. Surfactant suspended in saline was characterized by a nearly instantaneous adsorption (the surface tension recorded 1 $s$ after pulsation was stopped at maximum bubble size differed from the equilibrium surface tension by only $1 \mathrm{mN} / \mathrm{m}$ ), a maximum dynamic surface tension only $4 \mathrm{mN} / \mathrm{m}$ above the equilibrium value, and a minimum dynamic surface tension close to 0 $\mathrm{mN} / \mathrm{m}$. This satisfies currently applied in vitro criteria for a physiologically active surfactant preparation (12).

With edema fluid present in the sample there was, at all $\mathrm{P} / \mathrm{L}$ ratios studied, a trend toward increased equilibrium surface tension (to $26-27 \mathrm{mN} / \mathrm{m}$ ) (NS). There was also a delay in surface adsorption (surface tension recorded $1 \mathrm{~s}$ after pulsation was stopped at maximum bubble size was higher than the equilibrium value, especially at $\mathrm{P} / \mathrm{L}$ ratios $\geq 3.4$ ) and a corresponding increase in maximum and minimum surface tension during pulsation. Values for minimum surface tension showed a statistically significant increase only at $\mathrm{P} / \mathrm{L}$ ratios $\geq 3.4$. Nearly complete inhibition of surfactant activity was observed at a $\mathrm{P} / \mathrm{L}$ ratio of 4.5 (surface tension recorded $1 \mathrm{~s}$ after pulsation was stopped at maximum bubble size was almost twice as high as the equilibrium value, and very high values were obtained for both maximum and minimum surface tension during pulsation).

Body weights and heart rate of experimental animals. There was no difference in body weight between the various groups of animals (Table 2). ECG recordings at the end of the experiments revealed that only two control animals (one in each group) survived the period of ventilation with a heart rate $>100 / \mathrm{min}$. Significantly improved survival rates were found in all surfactanttreated animals except for the group receiving the lower concentration $(25 \mathrm{mg} / \mathrm{mL})$ mixed with edema fluid at a $\mathrm{P} / \mathrm{L}$ ratio of 11.2 (Table 2).

Tidal volumes. The tidal volume measurements are summarized in Figure 1. Control animals had very low average tidal volumes $(<5 \mathrm{~mL} / \mathrm{kg}$ body weight) at each of the pressure levels used for ventilation. Animals receiving natural surfactant suspended in saline had approximately 5-fold larger average tidal volumes, irrespective of whether the surfactant concentration was 25 or $50 \mathrm{mg} / \mathrm{mL}$. Replacing the vehicle of the surfactant suspension with edema fluid caused no significant change in tidal volumes at a $\mathrm{P} / \mathrm{L}$ ratio of 2.2 at the lower and 2.8 at the higher phospholipid concentration. Increasing the protein concentration to $280 \mathrm{mg} / \mathrm{mL}$ did not influence tidal volumes in

Table 1. Surface properties of surfactant suspended in normal saline or in various concentrations of edema fluid (EF) in saline*

\begin{tabular}{|c|c|c|c|c|c|c|}
\hline \multirow[b]{2}{*}{ Sample } & \multirow[b]{2}{*}{$\mathrm{P} / \mathrm{L}$} & \multirow[b]{2}{*}{$n$} & \multicolumn{4}{|c|}{ Surface tension $(\mathrm{mN} / \mathrm{m})$} \\
\hline & & & Equilibrium & Maximum & Minimum & $1 \mathrm{~s}$ \\
\hline Surfactant + saline & 0 & 5 & $25(0.9)$ & $28(0.9)$ & $0.7(0.4)$ & $26(1.1)$ \\
\hline Surfactant + saline + EF $(8 \%)$ & 0.45 & 3 & $27(1.1)$ & $34(4.0) \dagger$ & $0.8(0.4)$ & $31(2.9) \dagger$ \\
\hline Surfactant + saline + EF $(16 \%)$ & 0.90 & 3 & $27(0.8)$ & $34(1.7) \dagger$ & $2.2(1.2)$ & $30(1.5) \dagger$ \\
\hline Surfactant + saline + EF $(32 \%)$ & 1.8 & 3 & $26(1.4)$ & $34(1.7) \dagger$ & $1.0(0.5)$ & $31(2.5) \dagger$ \\
\hline Surfactant + saline + EF $(60 \%)$ & 3.4 & 3 & $26(2.2)$ & $42(17) \dagger$ & $10(13) \dagger$ & $40(17) \dagger$ \\
\hline Surfactant + saline + EF $(80 \%)$ & 4.5 & 3 & $27(1.4)$ & $55(4.7) \dagger$ & $22(1.0) \dagger$ & $52(4.8) \dagger$ \\
\hline
\end{tabular}

* The concentration of surfactant lipids is the same in all samples, $10 \mathrm{mg} / \mathrm{mL}$. Mean (SD) values for equilibrium surface tension before pulsation, maximum and minimum surface tension after $5 \mathrm{~min}$ of pulsation, and surface tension $1 \mathrm{~s}$ after pulsation was stopped at maximum bubble size (surface tension " $1 \mathrm{s"}$ ") are given in relation to the $\mathrm{P} / \mathrm{L}$ weight ratio of the sample.

$\dagger p v s$ surfactant + saline $<0.05$. 
Table 2. Number of animals, body weight, and survival with heart rate $>100 /$ min in experimental animals receiving surfactant at low or high concentration, mixed with various amounts of edema fluid (EF), and in littermate controls

\begin{tabular}{lccccc}
\hline \multicolumn{1}{c}{$\begin{array}{c}\text { Lipid } \\
\text { material }\end{array}$} & $\begin{array}{c}\text { concentration } \\
(\mathrm{mg} / \mathrm{mL})\end{array}$ & \multicolumn{1}{c}{ P/L } & $n$ & $\begin{array}{c}\text { Body weight (g) } \\
\text { mean (SD) }\end{array}$ & $\begin{array}{c}\text { Survival with } \\
\text { heart rate } \\
>100 / \mathrm{min}\end{array}$ \\
\hline Surfactant & 25 & 0 & 16 & $26(5)$ & $13 / 16^{*}$ \\
Surfactant + EF & 25 & 2.2 & 9 & $28(2)$ & $7 / 9^{*}$ \\
Surfactant + EF & 25 & 11.2 & 11 & $29(2)$ & $0 / 11$ \\
Controls & & & 19 & $24(6)$ & $1 / 19$ \\
Surfactant & 50 & 0 & 6 & $29(3)$ & $6 / 6 \dagger$ \\
Surfactant + EF & 50 & 2.8 & 9 & $28(4)$ & $6 / 9 \dagger$ \\
Surfactant + EF & 50 & 5.6 & 6 & $30(4)$ & $4 / 6 \dagger$ \\
Controls & & & 7 & $28(4)$ & $1 / 7$ \\
\hline
\end{tabular}

* $p$ vs controls $<0.001$.

$\dagger p$ (combined groups) vs controls $<0.02$.

animals receiving the larger dose of surfactant phospholipids ( $\mathrm{P} / \mathrm{L}$ ratio: 5.6 ) but caused, at each pressure level, a statistically significant fall in tidal volumes in animals treated with the lower dose of surfactant $(\mathrm{P} / \mathrm{L}$ ratio: 11.2$)$.

Morphometric data on alveolar expansion. Data from morphometric evaluation of alveolar expansion are shown in Table 3. The volume density of alveolar spaces was more than twice as high in animals treated with surfactant suspended in saline as in nontreated controls, irrespective of the concentration of the surfactant suspension. Animals receiving surfactant suspended in original or concentrated edema fluid showed the same order of improvement as the animals treated with surfactant suspended in saline.

\section{DISCUSSION}

These data show for the first time that the therapeutic effect of surfactant replacement in immature newborn animals is compromised by the presence of edema fluid in the airspaces. The protein content of the edema fluid $(56 \mathrm{mg} / \mathrm{mL})$ was only slightly lower than the normal range for serum proteins $(65-82 \mathrm{mg} / \mathrm{mL})$ and albumin as well as three peaks of globulin $\left(\alpha_{1}, \alpha_{2}\right.$, and $\left.\beta\right)$ could be identified by electrophoresis. Because the edema fluid was derived from lungs with a permeability problem due to hyperoxia-induced cellular damage, it probably contained other macromolecules as well, including membrane lipids from disin- tegrating alveolar and bronchiolar epithelium (7). We made no efforts to clarify which of these components was responsible for the observed inhibition of surfactant; other studies with pulsating bubble have revealed that a modified natural surfactant (Surfactant TA) is inhibited by several isolated serum proteins in a concentration-dependent manner, as well as by total serum and high concentrations of serum lipids (5). In the mixtures of edema fluid, saline, and Surfactant CK examined with pulsating bubble, the contribution of phospholipid (including surfactant phospholipids) by the edema fluid did not amount to more than $0.8 \mathrm{mg} /$ $\mathrm{mL}$ in samples containing the largest proportion $(80 \%)$ of edema fluid, and was of course less in samples in which the edema fluid was more diluted. This contribution is small in relation to the concentration of Surfactant CK in the samples $(10 \mathrm{mg} / \mathrm{mL})$ and cannot have influenced our results to any significant degree.

Our in vitro and in vivo data can be interpreted together by means of a theoretical model in which the hypophase of the samples studied with pulsating bubble is regarded as analogous to the various mixtures of fetal lung liquid, exogenous surfactant, and edema fluid that filled the lungs of the experimental animals at the onset of ventilation. These animals were delivered at a stage of gestation when the liquid-filled lungs contain very small amounts of endogenous surfactant lipids (13). The volume of the fetal lung liquid is approximately $30 \mathrm{~mL} / \mathrm{kg}$ body weight (14), corresponding to about $0.8 \mathrm{~mL}$ in the rabbit neonates listed in Table 2. To this liquid-filled compartment we added $0.1 \mathrm{~mL}$ of a surfactant suspension with a lipid concentration of 25 or 50 $\mathrm{mg} / \mathrm{mL}$ (corresponding to doses of about 90 and $180 \mathrm{mg} / \mathrm{kg}$ ). Although complete mixing may not take place, the average concentration of exogenous surfactant in the airspaces before the onset of ventilation and postnatal resorption of fetal lung liquid can be estimated to $2.8 \mathrm{mg} / \mathrm{mL}$ or $5.6 \mathrm{mg} / \mathrm{mL}$, respectively. The lower of these levels is close to the estimated "critical concentration" of surfactant lipids in the fetal lung liquid (about $3 \mathrm{mg}$ / $\mathrm{mL}$ ) required for rapid adsorption of the surfactant molecules to the air-liquid interfaces, low minimum surface tension during surface compression, and adequate lung volumes during ventilation (15). A surfactant lipid concentration of $5 \mathrm{mg} / \mathrm{mL}$ would allow some safety margin with respect to these requirements. Indeed, both dose levels of surfactant in saline used in the present experiments improved lung compliance to a similar degree, confirming earlier observations (10).

Assuming that very little protein is normally present in the airspaces of the nonventilated neonatal lung (14), the $\mathrm{P} / \mathrm{L}$ ratio of the same liquid ranged from 0-11.2 depending on the com-
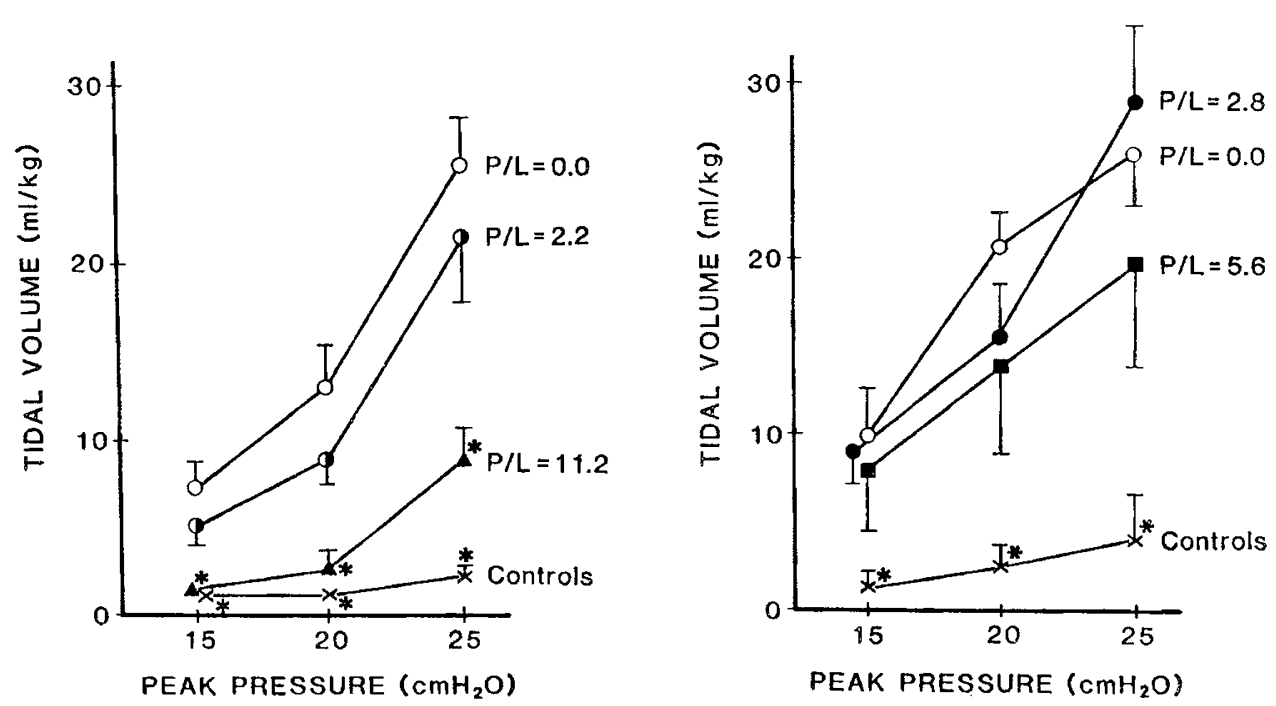

Fig. 1. Tidal volumes (mean, SEM) at insufflation pressures 15,20 , and $25 \mathrm{~cm} \mathrm{H} \mathrm{H}_{2} \mathrm{O}$ in animals receiving various mixtures of surfactant and edema fluid, and in littermate controls. ${ }^{*} p$ vs $(\mathrm{P} / \mathrm{L}=0.0)<0.05$. 
Table 3. Volume density of alveolar spaces in experimental animals receiving surfactant at low or high concentration, mixed with various amounts of edema fluid $(E F)$, and in littermate controls

\begin{tabular}{lccc}
\hline \multicolumn{1}{c}{$\begin{array}{c}\text { Instilled } \\
\text { material }\end{array}$} & $\begin{array}{c}\text { Lipid } \\
\text { concentration } \\
(\mathrm{mg} / \mathrm{mL})\end{array}$ & $\mathrm{P} / \mathrm{L}$ & $\begin{array}{c}\text { Volume density } \\
\text { mean (SD) }\end{array}$ \\
\hline Surfactant & 25 & 0 & $0.58(0.10)^{*}$ \\
Surfactant $+\mathrm{EF}$ & 25 & 2.2 & $0.65(0.10)^{*}$ \\
Surfactant $+\mathrm{EF}$ & 25 & 11.2 & $0.56(0.10)^{*}$ \\
Controls & & & $0.25(0.08)$ \\
Surfactant & 50 & 0 & $0.70(0.03)^{*}$ \\
Surfactant $+\mathrm{EF}$ & 50 & 2.8 & $0.64(0.09)^{*}$ \\
Surfactant $+\mathrm{EF}$ & 50 & 5.6 & $0.66(0.05)^{*}$ \\
Controls & & & $0.33(0.15)$ \\
\hline
\end{tabular}

${ }^{*} p$ vs controls $<0.01$

position of the vehicle in which the exogenous surfactant was suspended. Nearly complete inhibition of in vivo surfactant activity, as reflected by very low tidal volumes even at an insufflation pressure of $25 \mathrm{~cm} \mathrm{H} \mathrm{H}_{2} \mathrm{O}$, was observed only at the maximum $\mathrm{P} / \mathrm{L}$ ratio, 11.2. This $\mathrm{P} / \mathrm{L}$ ratio is more than twice as high as the $\mathrm{P} / \mathrm{L}$ ratio level required for nearly complete inhibition of surfactant activity in the present (Table 1) as well as in earlier (7) pulsating bubble measurements. No in vivo inhibition was documented at a $\mathrm{P} / \mathrm{L}$ ratio of 5.6, when the concentration of exogenous surfactant amounted to $50 \mathrm{mg} / \mathrm{mL}$ (in vivo data for the corresponding $\mathrm{P} / \mathrm{L}$ ratio at the lower lipid concentration, 25 $\mathrm{mg} / \mathrm{mL}$, are not available).

These discrepancies may reflect oversimplification of the theoretical model used to explain our findings. Bubble samples are presumably well mixed, whereas this may not be the case for exogenous surfactant, edema fluid, and fetal lung liquid in the in vivo experiments. Surfactant lipids may, even in the presence of inhibitory proteins, orient preferentially near the air-liquid interfaces of the expanding lung, requiring relatively higher $\mathrm{P} / \mathrm{L}$ ratios for inhibition. In spite of these shortcomings, the combined data from our in-vitro and in-vivo experiments illustrate that the functional properties of a leaky, immature lung depend on the stoichiometric relation between surfactant lipids and inhibitory proteins in the airspaces.

Inhibition of surfactant function was demonstrated during dynamic conditions only (by reduced compliance), not in our "static" morphometric data (representing alveolar expansion pattern at $10 \mathrm{~cm} \mathrm{H}_{2} \mathrm{O}$ deflation pressure). We have observed analogous differences between data obtained during dynamic and static conditions in another series of experiments on immature rabbits, in which exogenous natural surfactant was mixed with large amounts of albumin ( $\mathrm{P} / \mathrm{L}$ ratio: 8$)$. The admixture of albumin seriously compromised the therapeutic effect of surfactant on tidal volumes, but had little influence on static pressurevolume recordings (which allow long periods for equilibration at each pressure level and, therefore, are not very sensitive to disturbances of surfactant adsorption rate) (16).

The design of the present experiments allowed us to demonstrate the inhibitory effect of edema fluid immediately after the onset of artificial ventilation. In the clinical situation, proteinaceous edema fluid gradually accumulates in the alveoli of a surfactant-deficient immature lung. Our results are nevertheless in keeping with the concept that, in babies with threatened or developing respiratory distress syndrome, comparatively large doses of surfactant, perhaps amounting to as much as $200 \mathrm{mg} /$ $\mathrm{kg}$ (17), should be administered as soon as possible after birth to avoid interference by surfactant inhibitors leaking into the airspaces.

\section{REFERENCES}

1. Jobe A 1984 Respiratory distress syndrome-new therapeutic approaches to a complex pathophysiology. Adv Pediatr 30:93-130

2. Grossmann G, Nilsson R, Robertson B 1986 Scanning electron microscopy of epithelial lesions induced by artificial ventilation of the immature neonatal lung: the prophylactic effect of surfactant replacement. Eur J Pediatr 145:361-367

3. Ikegami M, Jobe A, Jacobs $H$, Lam $R 1984$ A protein from airways of premature lambs that inhibits surfactant function. J Appl Physiol 57:11341142

4. Ikegami M, Jobe A, Berry D 1986 A protein that inhibits surfactant in respiratory distress syndrome. Biol Neonate 50:121-129

5. Fuchimukai T, Fujiwara T, Takahashi A, Enhorning G 1987 Artificial pulmonary surfactant inhibited by proteins. J Appl Physiol 62:429-437

6. Robertson B, Berry D, Curstedt $T$, Grossmann G, Ikegami M, Jacobs H, Jobe A, Jones S 1985 Leakage of protein in the immature rabbit lung; effect of surfactant replacement. Respir Physiol 61:265-276

7. Ennema JJ, Kobayashi T, Robertson B, Curstedt $T 1988$ Inactivation of exogenous surfactant in experimental respiratory failure induced by hyperoxia. Acta Anaesthesiol Scand 32:665-671

8. Kobayashi T, Grossmann G, Robertson B, Ueda T 1984 Effects of artificial and natural surfactant supplementation in immature newborn rabbits. $J$ Jpn Med Soc Biol Interface 15:125-131

9. Enhorning G 1977 Pulsating bubble technique for evaluating pulmonary surfactant. J Appl Physiol 43:198-203

10. Shido A, Kobayashi T, Ganzuka M, Taniguchi J, Kataoka H, Murakami S 1988 Concentration of replaced surfactant and the physiological effects. J Jpn Med Soc Biol Interface 19:52-59

11. Lachmann B, Grossmann G, Freyse J, Robertson B 1981 Lung-thorax compliance in the artificially ventilated premature rabbit neonate in relation to variations in inspiration:expiration ratio. Pediatr Res 15:833-838

12. Robertson B, Lachmann B 1988 Experimental evaluation of surfactants for replacement therapy. Exp Lung Res 14:279-310

13. Gluck L, Motoyama EK, Smith HL, Kulovich MV 1967 The biochemical development of surface activity in mammalian lung. I. The surface-active phospholipids; the separation and distribution of surface-active lecithin in the lung of the developing rabbits fetus. Pediatr Res 1:237-246

14. Strang LB 1977 Neonatal Respiration. Physiological and Clinical Studies. Blackwell, Oxford, pp 20-46

15. Kobayashi T, Shido A, Nitta K, Inui S, Ganzuka M, Robertson B 1990 The critical concentration of surfactant in fetal lung liquid at birth. Respir Physiol 80:181-192

16. Nitta K, Inui S, Kobayashi T, Shido A, Ganzuka M, Murakami S 1989 Evaluation of pulmonary surfactants by the use of immature animals. Hokuriku J Anesthesiol 23:13-17

17. Collaborative European Multicenter Study Group 1988 Surfactant replacement therapy for severe neonatal respiratory distress syndrome: an international randomized clinical trial. Pediatrics 82:683-691 